\title{
Student-centred teaching in Initial Teacher Education
}

\author{
Leah O'Toole, \\ Marino Institute of Education, \\ An Associated College of Trinity College, Dublin \\ Ireland
}

\begin{abstract}
The student-centred approach to teaching advocated by Carl Rogers [1, 2] and others [3] maintains that significant learning is most effectively promoted through facilitation of self-initiated, responsible action. Rogers [2] describes his approach to teaching Psychology at university level with no prepared agenda, but rather beginning each class by asking "What would you like to learn about today?" According to Rogers [2], the structure and organisation of self becomes more rigid under threat, and relaxes its boundaries when free from threat. Educational situations conducive to learning, therefore, ensure that 'threat' is reduced to a minimum. Thus, the role of a student-centred teacher is to create the kind of atmosphere in which students have the 'freedom to learn' [1], and all learning, it is hypothesised, takes place in the context of 'the relationship' between student and teacher.

This paper explores the tensions inherent in attempting to implement a student-centred approach in the current era of 'modularisation', 'learning outcomes' and 'accountability' in Initial Teacher Education in Ireland. The innovative approaches described were developed in teaching undergraduate student teachers in Marino Institute of Education, Dublin, Ireland. They include self-directed learning through student choice of topics; use of technology such as Twitter and Moodle, both in-class and beyond, to facilitate freedom of expression and engagement, smaller class sizes to support individualised approaches, and a focus on 'the relationship' between lecturer and students as a key element of the learning environment. Analysis of student feedback through qualitative, semi-structured questionnaires indicates that student-centred approaches still represent powerful pedagogical methodologies, even in the context of a contemporary neo-liberal educational climate.
\end{abstract}

\section{Introduction}

The student-centred approach to education grew out of the work of Humanist psychologists who emphasised concepts of human capacity and growth, self-direction, and a respectful 'valuing' of each human being. A key influence on the development of such methods and educational philosophies was the American psychologist Carl Rogers. Rogerian psychology originally stemmed from a therapeutic orientation relying primarily on the capacity of the client; in other words it focused on the ability of the client to direct the course of their own lives [2]. Rogers describes the capacity of all humans to achieve insight or constructive self-direction, and to deal with his or her psychological condition for all aspects of life that can potentially come into conscious awareness.

In Rogers' client-centred therapy, the counsellor's role is to create an interpersonal situation in which material can come into client's awareness through meaningful demonstration of the counsellor's acceptance of the client as a person who is competent to direct him or herself [2]. Rogerian therapeutic techniques very simply involve listening to the person, and reflecting back to them what they have said in an accepting and understanding manner. For Rogers, this respect for self-direction applies even when the person seems to choose goals that seem antisocial - Rogers [2] asks whether the counsellor

"is willing for the client to choose regression rather than growth or maturity? To choose neuroticism rather than mental health? To choose to reject help rather than accept it? To choose death rather than life? To me it appears that only as the therapist is completely willing that any outcome, any direction may be chosen - only then does he realise the vital strength of the capacity and potentiality of the individual for constructive action." (p 48)

Within this orientation, therapists view the person as capable of directing the course of their own lives, and the function of therapy is to provide a supportive relationship within which this capacity can be exercised. The relationship between therapist and client provides the client with the opportunity of making responsible choices in an atmosphere in 
which it is assumed that he is capable of making decisions for himself.

Unlike other therapeutic orientations which demand objectivity and separateness from the therapist, a Rogerian therapist is highly important part of the human equation - "what he does, the attitude he holds, his basic concept of his role, all influence therapy to a marked degree" [2, p 19]. Rogers requires therapists to exhibit three central characteristics: Congruence (genuineness), unconditional positive regard (acceptance, trust) and empathy (understanding from the client's viewpoint - or 'internal frame of reference') [2]:

"The primary point of importance here is the attitude held by the counsellor toward the worth and significance of the individual. How do we look upon others? Do we see each individual as having worth and dignity in his own right?... Do we tend to treat individuals as persons of worth or do we subtly devalue them by our attitudes and behaviour?... Do we respect his capacity and his right to self-direction or do we basically believe that his life would be best guided by us?... Are we willing for the individual to select and choose his own values or are our actions guided by the conviction (usually unspoken) that he would be happiest if he permitted us to select for him his values and standards and goals?" (p 20).

In an educational setting then, the role of a teacher using this approach is to create a supportive, trusting relationship through their own congruence, unconditional positive regard and empathy. In other words this means moving beyond deficit models of behaviour and learning, and respecting each student as an individual capable of positive growth [2]. Rogers [2] maintains that the greatest tool a therapist or a teacher has in supporting the client or the student is acceptance. Acceptance of the student does not mean passivity or indifference - a lack of involvement is experienced as rejection. What is recommended by Rogers is a very active engagement, or to use Urie Bronfenbrenner's terminology, 'bidirectional reciprocity of exchange' [4]. In Rogerian therapy, the counsellor's role is partly to objectify and clarify the client's feelings [5]:

"As material is given by the client, it is the therapist's function to help him recognise and clarify the emotions which he feels" (p 169).

The counsellor must assume the client's 'internal frame of reference' - to perceive the world as he or she sees it, to perceive the client as he or she is perceived by himself, to lay aside all perceptions from the external frame of reference, and to communicate something of this empathetic understanding to the client [2]. A teacher working with a student must therefore try to see the world through his or her eyes and make it very clear that this is what they are trying to do [2].

What is recommended by Rogers [2] is an active experiencing of the feelings expressed. It is not an emotional identification but an empathetic identification - in other words, perceiving the feelings of the client or student without feeling them oneself. Focusing the whole of one's attention and effort on understanding a person's perceptions and feelings is a striking demonstration that the counsellor or teacher believes in the worth and significance of the client or student [2]. The central aim of therapy or education within this orientation is to support the person to figure things out for him or herself, rather than telling him or her what the right solution is. Rogers [2] cites a patient who said "In conferring with the counsellor I listened to myself while talking. And in doing so I would say that I solved my own problems". This is the essence of client-centred therapy - supporting people to solve their own problems through the power of 'the relationship'.

As such, Rogers' concept of person-centredness has been transferred from therapy to the educational arena through these ideas of self-direction and the importance of the relationship, and this forms the essence of 'student-centred teaching' [2]. His educational ideas have much in common with constructivist approaches such as those of Vygotksy [6] and Bruner [7] in terms of allowing children to discover learning for themselves, and the role of the teacher as facilitator rather than direct instructor. Rogers' ideas on student-centred teaching also have much in common with democratic approaches to education advocated by Dewey [8]. Student-centred approaches have been shown, in the intervening decades since Rogers' original expositions, to be remarkably effective in terms of the development of pro-social, self-regulated behaviour [3], motivation and engagement, and positive academic outcomes [1].

\subsection{Student-centred teaching in Initial Teacher Education}

The student-centred approaches reported in this paper were largely inspired by a presentation given by Rogers in 1973 [9] entitled 'Questions I would ask myself if I were a teacher'. The first 'question' asked by Rogers was "what is it like?", and the teaching approaches used here sought to draw on this question with student teachers studying Psychology within a three-year B.Ed degree. Questions explored included "What is it like to be a student teacher?", 
"When were the times that you were in a classroom setting and wished that there was a psychologist beside you to support you?", "What is important to you in your life as a human being and as a student teacher?", "What would you like to learn about in this course?"

Rogers' [9] second question (or rather series of questions) was also highly relevant to this research: "Do I dare to let myself deal with this boy or girl as a person, as someone I respect? Do I dare reveal myself to him and let him reveal himself to me? Do I dare to recognize that he/she may know more than I do in certain areas - or may in general be more gifted than I?" A key element of the approaches reported here involved allowing students to see the lecturer as a human being, with fears and imperfections just like everyone else. For example, when describing Rogers' approaches with his own college students (completely non-directive classes with no prepared agenda) the lecturer confessed her own fears and insecurities at the idea of taking such an approach, regarding potential perceptions on behalf of students and colleagues of unprofessionalism, insecurities of being under-prepared or not knowing enough about a certain topic, and fears of limited student engagement due to lack of structure. Some students in this cohort replicated the shock reported by Rogers [9] on behalf of medical students on discovery that faculty members using these approaches were in fact human beings. Equally it was challenging for the lecturer to expose imperfections, to acknowledge that in some areas (for example experience directly teaching large groups of young children) the students had more expertise than she did. Nevertheless, as predicted by Rogers [9] much was to be gained by "step[ping] off the pedestal of the 'teacher' and becom[ing] a facilitative learner among learners”.

Equally, Rogers' [9] next two questions, "What are the interests, goals, aims, purposes, passions of these students?" and "How can I preserve and unleash curiosity?", were also key to this research, which sought to find out through person-centred methods what student teachers wanted to gain from a Psychology class. What did they feel it was important for them to learn? What would help them to become better teachers and find insight as human beings? Rogers [9] recommends asking these questions directly as well as creating a supportive environment in which students feel willing and able to share these things without being directly asked. As such, the student-centred approaches reported in this paper included supporting expression of student voice, developing student capacity for engagement and in-class contribution, and emphasis on selfdirected learning, all of which combined to foreground both the relationship between students and the lecturer, and the creation of a learning environment free from threat.

\subsection{The 'Global Education Reform Movement' - the antithesis of a student- centred approach?}

However, the implementation of these ideas was not without its challenges in the broader context of higher education in Ireland. Practices based on an individualised, self-directed concept of education are coming under increasing pressure in Ireland and internationally, and may even be at risk of being marginalised, in the current world climate of standardisation in education under the guise of 'accountability' [10, 11, 12, 13].

Ó Breacháin and O'Toole [11] describe the spread of certain educational ideas around the globe, and how potentially damaging approaches can be 'blindly' implemented as a result of political rather than pedagogical considerations. One such educational movement has been wryly dubbed 'the GERM' (Global Education Reform Movement) by Sahlberg [14, 15], and this refers to the increasing neo-liberal emphasis on standardisation as opposed to individualised approaches to education, accountability as opposed to creativity [12], and a move away from holistic conceptions of education as development, toward narrow subject based curricula $[11,16]$

This presents a challenge to educators at third level, since young people, through their 'apprenticeship of observation' [17], may come to believe that 'intelligence' means the ability to score highly on standardised tests, and that a 'good' educator simply prepares them to do so [18]. By the time they get to college, many students are 'deadened' by educational experiences to date. In 1973 Rogers [9] indicated that,

"As children go through our public school system they become less inquiring, less curious... it seems that we do everything possible to kill, in our students, this inquisitiveness, this wide ranging, searching wonder about the world and its inhabitants."

This may certainly be true in the Irish context with increasing emphasis in recent years on standardised test scores, even from primary level, in the wake of the publication of the National Literacy and Numeracy Strategy [19]. It has been argued that this has threatened the previously holistic focus on a 'broad and balanced curriculum' in Irish primary education [11], and this is most certainly evident at secondary level in Ireland. Here the focus is on highstakes testing (Leaving Certificate) and the 'points 
race' with its emphasis on regurgitation of enough 'facts' to score enough 'points' to get into third level education, rather than on fostering a love of learning or a curiosity about life. The study of educational psychology and the study of teaching are both aimed at people who are fascinated by children, how they develop and how they learn. The approaches reported here aimed to reignite the passionate curiosity about children that brought most students into teaching in the first place, and to ensure they knew that it was perfectly acceptable to question and ponder and research and debate, rather than being expected to give the 'right' answer in order to pass an exam, as may have been their previous experience in education.

However, the current neo-liberal emphasis in education in Ireland and elsewhere presents another challenge to third-level educators attempting studentcentred approaches, beyond simply attempting to change the attitudes and understandings of their students. Olssen and Peters [20] have identified a 'fundamental shift' in higher education institutes, away from intellectual inquiry and debate, and towards performativity, measured outputs, quality assurance and academic audits. A lecturer at third level developing an academic module in Ireland is now expected to identify standardised learning outcomes and assessment measures, and to modularise their courses in accordance with the Bologna agreement, a process launched in 1999 by the Ministers of Education and University leaders of 29 countries $^{1}$ which aims to harmonise Europe's higher education [21]. For example, the structure of 'learning outcomes' is expected to be standardised through the use of specific verbs related to knowledge, comprehension, application, analysis, synthesis and evaluation [22]. Some illustrative examples of the learning outcomes identified in advance for the two courses under consideration in this paper included:

"On successful completion of this module, the student will be able to...

- Identify the multitude of factors interacting and impacting on learning and motivation.

- Synthesise various theoretical approaches to explaining how children learn, and critically analyse how different psychological theories compare and contrast.

- Assess the political nature of curriculum and assessment regarding issues of inclusion and social justice."

\footnotetext{
${ }^{1}$ At time of writing, involvement in the Bologna agreement had expanded to 46 countries (http://www.eua.be/eua-work-andpolicy-area/building-the-european-higher-education-area/bolognabasics.aspx)
}

Such standardised approaches to understanding the processes of learning may provide challenges to the educator who aims to adapt teaching and learning methods, and even content, based on the needs and preferences of individual students. Equally, Bologna structures require that educators measure achievement of learning outcomes through the use of standardised, objective forms of assessment. This is in significant opposition to Rogers' [2] assertion that the only person who can measure the quality and extent of learning is the learner him or herself, and so his advocacy of self-assessment. The current research therefore addresses the question of whether it is possible to maintain the philosophy and methodologies of student-centred teaching in Initial Teacher Education in contemporary Ireland.

\section{Methodology}

\subsection{Sample and instrument}

This research investigates the application of a student-centred approach to teaching two courses, 'Educational Psychology' and 'Curriculum and Assessment', to a cohort of 104 student primary school teachers (B.Ed) in the Marino Institute of Education, Dublin, Ireland in the academic year 2013-2014.

Located within an interpretive paradigm, the research sought the perspectives (or 'internal frame of reference' to draw on Rogerian terminology) of students on their experiences of the approaches used. Students responded to a semi-structured qualitative questionnaire, and responses were probed through content analysis on themes related to student-centred teaching. 67 of the 104 students responded, and it is worth noting that, consistent with the gender profile of student and practicing teachers in primary education in Ireland, and the increasing feminisation of the sector [23], gender in this sample was strongly skewed ( $\mathrm{n}=67 ; 6$ male, 61 female).

\subsection{Specific Approaches: Supporting expression of student voice}

In beginning to implement more student-centred approaches with this cohort, the lecturer began, as advocated by Rogers, with the 'internal frame of reference' of students. At the end of term 1 (December 2013), a class evaluation was conducted, with the aim of identifying student insights on how the courses were going for them. Responses were largely positive but there was some level of disengagement reported, and Psychology was perceived by many students as being a very challenging subject to study. Ideas and suggestions to facilitate and support their learning were elicited, 
and these included a change to the formatting of 'powerpoint' notes, explicit identification of learning objectives for each lecture, summarising content at the end of each lecture and extension of the existing use of group work. All of these suggestions were incorporated into the teaching methods used for term 2 (January to May, 2014).

\subsection{Specific Approaches: Development of student capacity for engagement and in-class contribution}

One of the central findings of the course evaluation at the end of term 1 was that many students found the large class-size to be a major barrier to their learning, and intimidation speaking out in front of a class of 104 colleagues presented a significant limitation to their engagement. In order to address this difficulty, the cohort was divided into three groups of approximately 34 students for the Curriculum and Assessment module for term 2, with the aim of facilitating confidence, discussion and debate in the smaller classes.

The timetable did not allow for this approach to be implemented for both modules, so again the researcher drew on Rogers' [9] list of 'questions I would ask myself if were a teacher', asking 'How can I imaginatively provide resources for learningresources that are both physically and psychologically available?" The answer to this question was found in the use of social media, specifically 'Twitter'. This was employed in the Educational Psychology module as an alternative means of contributing a comment or question without having to speak out in front of a large group of peers. The support of the ICT lecturer was elicited, and a lecture was provided to both the group of students and the Psychology lecturer on the intricacies of Twitter use, including both technical details (how to 'tweet') and considerations of etiquette (professionalism and avoidance of any form of 'cyberbullying'). Subsequent to this, a 'hashtag' was identified for students at the beginning of each Educational Psychology lecture, and students could then 'tweet' during the lecture. The Twitter 'feed' was managed and directed to the lecturer in real time by a volunteer student 'Twitter secretary' in each lecture. Questions and comments submitted through Twitter were addressed in the same way as those directly voiced.

\subsection{Specific approaches: Emphasis on self- directed learning}

A number of structural changes were also made in order to support the development of self-directed learning by students. The topics to be studied in
Educational Psychology were chosen in advance by students based on their perceived needs as novice teachers. In a similar approach to Rogers' use of the question 'what would you like to learn about today?', this choice was initially facilitated through in-class brainstorming on the theme of "times I wished I had a psychologist beside me in a school setting to support me'. This initial discussion yielded too many potential areas of study to be covered within the lectures available to the class, so a poll was set up on the class on-line learning system 'Moodle', and all students could vote on which topics they felt would be most important to study. This democratic approach to curriculum development yielded a list of concerns very relevant to the practice of student and newly qualified teachers, including bereavement, trauma, motivation, bullying, positive psychology, giftedness, parental alcoholism, and the impact of technology and social media on children's learning. In contrast to Rogers' approach, it also allowed both the lecturer and students time to prepare for lectures, and limited the time spent deciding on a direction to one session, rather than having to allocate time to such discussion at the beginning of each lecture. The on-line element also ensured that decisions were not made only by those students with the strongest voices.

Within the Curriculum and Assessment module, self-directed learning was facilitated by the smaller class sizes, and in-class methodologies relied heavily on student-led debate and discussion on topics around the socio-politics and psychology of curriculum and assessment. Students debated concepts of narrowing of curriculum, 'accountability' and standardisation, and the benefits and challenges associated with Ireland's models of curriculum and assessment when compared with other jurisdictions. When particular students raised pertinent issues (for example class sizes in Finland, or Teacher Education in the UK) they were asked to investigate further and bring the information back to the rest of the class. Students also often identified relevant readings or websites for their colleagues. In particular, these explorations drew on another of Rogers' [9] 'questions', "Can I help the student develop his feeling life as well as his cognitive life?", and a key area of discussion was the concept of holistic education, incorporating both 'thinking' and 'feeling'. Deconstruction of students' own experiences of learning since childhood was facilitated and gently encouraged, so that course outcomes might include learning by the whole person rather than simply meeting course requirements - as noted by Rogers [2], something difficult to achieve but highly rewarding in its end product. 


\section{Findings}

Content analysis of student responses to the semistructured questionnaires yielded overwhelmingly positive perceptions of the approaches used.

"I have learned more than I could have imagined in this course. It has been so in-depth but has been so easy to access and understand."

"I felt these two courses were very beneficial to me at Marino... I enjoyed the content and methodologies that you used with us. I have learned a vast amount by doing these two courses. Thank you very much for a beneficial and rewarding year."

Responses also offered strong support for the central concepts and philosophies inherent in student-centred teaching:

\subsection{The relationship between students and teacher, and feeling 'valued'}

Many students identified the importance of the relationship between the students and the lecturer:

"I really felt that the lecturer cared for our education. This makes such a difference. The best encouragement to learn is knowing that someone cares that / if you do"

"You invested such interest in our learning, it's obvious you genuinely want us to do well"

Respondents also noted how powerfully they were impacted by the sense of feeling 'valued', and that even from the first evaluation at the end of term 1 , the dynamic in the classes shifted somewhat, due to students' sense that their opinions and needs mattered:

"[The lecturer] actually listened to students" feedback and took on board everything she could. Knowing a lecturer actually cares about the class' wants makes it all the easier."

"Felt that feedback was listened to and valued. Found it helpful to have feedback / evaluation sheets during the term as often students are unhappy but do not get chance to evaluate until end of year which is too late."

"I felt the course was going very well before feedback anyway but it is great to feel your opinion is being valued"
"It is encouraging to feel listened to so when the format changes [based on our feedback] it feels like the learning is for us. It's empowering."

\subsection{The importance of a positive learning environment}

Rogers' emphasis on the creation of a learning environment facilitative of 'freedom to learn' was also supported by this cohort of students.

"Really enjoyed lectures, great atmosphere in the classes, always really positive learning environment which helped motivate me to learn and participate in the lectures as much as possible."

Smaller class sizes for the Curriculum and Assessment module were identified as a key element facilitative of the creation of such positive learning environments.

"Really liked this idea! Even from the first lecture I felt the benefits. Felt more personal and the condensed setting made the delivery of the lecture even more engaging than they already were in the whole year setting."

"This worked exceptionally well. More comfortable taking part and I know a lot of my friends also enjoyed this and found it worthwhile."

"This was very effective. Great opportunity for class debates and discussions which a lot of us commented on. Easier to ask questions in a smaller group."

\subsection{The importance of intrinsic motivation and self-directed, authentic learning}

Students also identified the importance of intrinsic rather than extrinsic motivation to learn, consistent with Rogers' emphasis on self-directed, authentic learning. The variety of teaching and learning approaches used (e. g. group-work, individual work, discussion, direct lecture, readings, tasks) was noted as supportive of authentic participation because different learning styles were catered for. The use of Twitter was also identified as strongly facilitative of the development of intrinsic motivation and genuine learning. Its use elicited overwhelmingly positive feedback, particularly with regard to student engagement. Respondents indicated that they felt excited and interested by it, and that this influenced their participation: 
"I remember sitting listening really hard to what was being done so I could be in on the action and tweet. I learned!!"

"Thought it was an excellent resource. People became more engaged in class and found the lectures interesting, they wanted to tweet something, resulting in total engagement."

Respondents also indicated that the use of Twitter had met the objective of supporting students to overcome any intimidation they felt about speaking out in a large group of 104 colleagues:

"I think using Twitter to support student feedback and engagement was a very modern way of giving the students another method of voicing their opinions. Sometimes it can be quite daunting to put yourself forward during a lecture to speak and I think it was a great help to students."

"I loved this strategy. Everybody was on an equal level and there was no immediate pressure. Seeing other people's tweets sparked our own questions and there was no intimidation of asking the question over Twitter with someone else reading it out."

An additional benefit of the use of Twitter was identified with regards to support for later independent study:

"I think it was very beneficial. There was a record then of questions asked which was useful for referring back to after lectures."

Some respondents did note less engagement with Twitter as time went by but they felt that this was because they and their colleagues were empowered by this and the other student-centred approaches to speak out more directly:

"Twitter gave people the opportunity to engage with the lecture without fear. In fact, by the end of the module, people seemed more comfortable talking out during the lectures because of the confidence gained by Twitter."

As such, regardless of some reduction of use over time, it would seem that the use of Twitter met its purpose in creating an educational atmosphere free from 'threat' as advocated by Rogers.

Equally, the opportunity to choose the topics studied in class was identified as key to engagement, motivation and learning, because the areas explored were perceived as 'useful' in contrast to a traditional perception of a 'disconnect' between the 'foundation' studies such as Psychology, and the actual practice of teaching [24].

"Excellent! I felt I was learning about the things I wanted to learn about. The topics chosen were ones that a lot of us have genuine concerns about and it will help us greatly in practice in the future."

"I really liked this aspect of the course. I was more engaged than last term as it was things I was interested in. It gave us, the students, a chance to learn about things we are worried about or things we had seen before."

"I really liked this approach as there was certain topics I really wanted to cover as situations had arose [sic] on teaching practice which I didn't feel equipped to handle. The topics were very much subjects we will face in the classroom and were very interesting."

"Excellent idea. I was personally a lot more engaged in these lectures as they related to everyday situations which a lot of us have encountered and will no doubt in the future. Linking to research and findings put Psychology in a much more accessible and practical place for me and I found myself participating more as I actually could from experiences. Normal Psychology for me was quite 'heavy' and I found it difficult to comprehend at times."

In fact, some students indicated that they felt that the courses had supported their development as human beings, beyond simple academic or professional learning:

"Your lectures have truly been an education. From first year you've been a source of guidance, encouragement and support. You've been so influential in my growth and development as a teacher and as a person. I hope you continue to enjoy your time in Marino. Thanks for the education!!”

"Although I found it difficult and upsetting, I found the trauma lectures very interesting and it helped me with understanding of my loss and almost made me feel normal!"

Others felt that their experiences would influence the types of teachers that they would become themselves:

"This is a topic I would have found quite difficult but you were able to make it all click for me. I really enjoyed the lectures, particularly the small lecture discussions and will miss it every 
Thursday morning. I hope to take what I've learned here and use it in a positive way in the classroom. [It was] an excellent example to me and I've learned so much here."

"It feels innovative when really it should always be that way. Makes me reconsider how I will structure my planning as a teacher".

As such, the responses of this cohort of students yielded significantly positive analysis of approaches to third level education based on Rogers' philosophies of student-centred teaching, particularly with regard to relationships and feeling valued, the importance of a positive learning environment, and facilitation of intrinsic motivation and authentic learning.

\subsection{Student-centred teaching in the era of accountability}

However, this cohort of students also demonstrated awareness of the demands of 'accountability' in the practice of teaching, and they largely expected similar 'professionalism' from the lecturer. The majority indicated that they would not approve of Rogers' approach of deciding what to study based on individual preferences at the beginning of each lecture, but rather they felt that the practice of making those decisions at the beginning of term was preferable:

"I feel that as teachers we like things to be structured a little so [Rogers'] approach may be a little difficult. Choosing topics in advance is a great compromise and suited me perfectly."

"Excellent approach - as students chose topics they had interest in and the lecturer had time to prepare them. Students were fully engaged as a result"

"No [it wouldn't be a good idea to just ask on the day]. If that were to happen the lecturer is not prepared for the topic. No resources would be immediately available for the topic. What one student wants to learn might differ to others how can 100 students agree on one topic they want to learn about? However, telling the lecturer in advance worked very well."

"I don't think this would work well as it would mean there would be very little structure. A good compromise is what we have done - choosing topics at the beginning. We had a choice but still had structure and knew what we were working towards."
As such, while support from respondents for student-centred methods was very strong, this was in the context of a preference for their adaptation to allow for preparation and development of resources in advance of lectures. It is worth noting that even with the individualised nature of the teaching and learning methods used in these two courses, they still allowed for students to meet the learning outcomes identified in advance, and for assessment of those learning outcomes to be somewhat standardised as required by the Bologna processes.

\section{Conclusions}

The responses of this cohort of students to their experiences of student-centred teaching yielded strong support for the pedagogical philosophies and methodologies advocated by psychologists and educators such as Carl Rogers. They also indicated that it is possible to adapt the original methodologies so that the requirements of 'standardisation' and 'accountability' can still be met by educators at third level. As such, student-centred teaching may offer a powerful vehicle for educators to work within a neoliberal system without being 'of' the system.

\section{References}

[1] Rogers, C. R. (1970, 1983, 1994) Freedom to learn, Merrill, Columbus.

[2] Rogers, C. R. (1995) Client-centered therapy: Its current practice, implications and theory, Constable, London.

[3] Freiberg, H. J. and Lamb, S. M. (2009).

'Dimensions of Person-centred Classroom

Management', Theory into Practice (48), pp. 99-105.

[4] Bronfenbrenner, U. and Morris, P. A. (2006)

'The Bioecological Model of Human Development', in R. M. Lerner, \& W. E. Damon (2006). Handbook of child psychology: Vol 1, Theoretical models of human development. John Wiley \& Sons Inc, Wiley and Sons, West Sussex.

[5] Rogers, C. R. (1940) Some newer concepts of psychotherapy, Mimeographed pamphlet, Ohio State University, Columbus.

[6] Vygotsky, L. S. (1978) Mind and society: The development of higher mental processes, Harvard University Press, Cambridge, MA.

[7] Bruner, J. (1990) Acts of Meaning, Harvard University Press, Massachusetts. 
[8] Dewey, J. (1916) Democracy and education, Southern Illinois University Press, Carbondale.

[9] Rogers, C. (1973). 'Questions I would ask myself if I were a teacher'. Revision of a talk given to a Conference on the Gifted and the Talented, Squaw Valley, California, July, 1973, Reprinted from Education, 95, p. 2.

[10] Berry, J. and Sahlberg, P. (2006).

'Accountability affects the use of small group learning in school mathematics', Nordic Studies in Mathematics Education (11, 1), pp. 5-31.

[11] Ó Breacháin A. and O’Toole, L. (2013). 'Pedagogy or Politics?: Cyclical Trends in Literacy and Numeracy in Ireland and Beyond', Irish Educational Studies (32, 4), pp. 401-419.

[12] Sahlberg, P. (2011) Finnish lessons, Teachers College Press, New York.

[13] Velde Pederson, P. (2007). 'What is Measured is Treasured: The Impact of the No Child Left Behind Act on Nonassessed Subjects', The Clearing House 80, 6, 287-291.

[14] Sahlberg, P. (2007). 'Education policies for raising student learning: The Finnish approach', Journal of Education Policy (22, 2), pp. 147-171.

[15] Sahlberg, P. (2009) 'Educational change in Finland', in A. Hargreaves, M. Fullan, A. Lieberman, and D. Hopkins (Eds.), International handbook of educational change (2nd ed.), Kluwer: New York.

[16] Alexander, R. J., and Armstrong, M. (2010) Children, their World, their Education: final report and recommendations of the Cambridge Primary Review, Routeledge, London.

[17] Lortie, D. C. (1975 / 2000) Schoolteacher: A sociological study, University of Chicago Press, Chicago.

[18] Smyth, E. and Banks, J. (2012). 'High Stakes Testing and Student Perspectives on Teaching and Learning in the Republic of Ireland', Educational Assessment, Evaluation and Accountability $(24,4)$, pp. 283-306.

[19] Department of Education and Skills (DES) (2011) Literacy and Numeracy for Learning and for Life, Stationery Office, Dublin.

[20] Olssen, M., \& Peters, M. A. (2005).

'Neoliberalism, higher education and the knowledge economy: from the free market to knowledge capitalism', Journal of Education Policy (20, 3), pp. 313-345.

[21] Reinalda, B., \& Kulesza-Mietkowski, E. (2005) The Bologna process: Harmonizing Europe's higher education, Barbara Budrich, Farmington Hills, MI.

[22] Bloom, B.S. (Ed.), Engelhart, M.D., Furst, E.J., Hill, W.H., \& Krathwohl, D.R. (1956) Taxonomy of educational objectives: The classification of educational goals. Handbook 1: Cognitive domain, David McKay, New York.

[23] McDonagh, S. and O'Toole, L. (2011) The feminisation of education, Unpublished M.Ed thesis, St Patrick's College, Drumcondra.

[24] Ryan, A. and O’Toole, L. (2014) 'Towards integrated learning: Linking Psychology and Sociology in Initial Teacher Education', in L. Daniela, I. Lūka, L. Rutka and I. Žogla (Eds.), Teacher of the $21^{\text {st }}$ Century, Quality Education for Quality Teaching, Cambridge Scholars Publishing, Newcastle-upon-Tyne, pp. 106-131.

\section{Acknowledgements}

The author would like to acknowledge the help and support of Anne McMorrough, Lecturer in ICT and e-Learning in the Marino Institute of Education, in the development of the approaches reported in this paper.

The author would also like to thank the students of Marino Institute of Education, in particular the graduating class of 2014, for the key role they played in the successes reported. 